\title{
Pengaruh Kecintaan Siswa Pada Al-Qur'an Terhadap Perilaku Sosial Di Sekolah Dasar Al Islam Plus Kabupaten Sidoarjo
}

\author{
Benny Angga Permadi, \\ Institut Pesantren KH. Abdul Chalim Pacet Mojokerto Indonesia \\ e-mail: bennyangga68@gmail.com
}

Submitted: 14-02-2021 Revised : 20-03-2021 Accepted: 21-04-2021

\begin{abstract}
Students nowadays are reluctant to go to the mosque to learn Quran. Their characters are influenced by technology such as television, internet, and video game which then make parents and teachers worried and anxious if they will act negatively. This thesis uses research design of mixed method with the objective to complete the image of research result about the phenomenon and to strengthen the analysis. The research strategy is done by combining the data from observation, interview and questionnaire in order to get qualitative and quantitative data. The data analysis is continuous qualitative-quantitative analysis, it is done by analyzing qualitative data and followed by analyzing the data through quantitative one. The bypothesis testing is done by using simple linier regression analysis with SPSS 18 program. The result of qualitative data is the students' affection on Quran in Islamic Elementary School through Quran memorizing program. Students' social behaviour is positive, whether toward friends and teachers in school. The result of quantitative data shows that students affection on Quran is $44 \%$ categorized as high, $40 \%$ as fair, and 16\% as low. Students' social behaviour shows that $74 \%$ as high, $10 \%$ as fair and $16 \%$ as low. The hypothesis testing uses t-test and the result of tcount is 6.356 with the significance of 0.026 . The tcount $>$ ttable $(6.356>2.010)$ or sig. $t<5 \%(0.026<0.05)$, it can be concluded that the variable of students' affection on Quran has significant influence toward the variable of students' social behaviour. The students' social behaviour is influenced by 55\% of variable of students' affection on Quran while $45 \%$ is influenced by other variable outside this research
\end{abstract}

Keywords: The Koran, Social Behaviour, Student Love

How to Cite Permadi, B. A., (2021). Pengaruh Kecintaan Siswa Pada Al-Qur'an Terhadap Perilaku Sosial Di Sekolah Dasar Al Islam Plus Kabupaten Sidoarjo. Attadrib: Jurnal Pendidikan Guru Madrasah Ibtidaiyah, 4(1), 35-38

\section{INTRODUCTION}

Kecintaan terhadap al-Qur'an merupakan istilah yang ringan diucapkan, tetapi penerapan dalam kehidupan sehari-hari bukanlah perkara yang mudah (Syukriyah, 2019). Cinta selalu membutuhkan perjuangan, pembuktian dan pengorbanan. Apabila seseorang mengatakan cinta kepada al-Qur'an, maka seseorang harus berusaha membuktikan cintanya tersebut dengan amal dan perbuatannya sehari-hari, apabila cinta tersebut diucapkan oleh mulut saja dan tidak ada bukti yang nyata, maka cinta itu adalah sebuah kebohongan (Kosim et al., 2019; Shihab, 1992). Dengan membuktikan cinta kepada pasangan hidupnya dengan berusaha memberikan yang terbaik dan memberikan apa saja kemauan pasangan hidupnya(Damis, 2014). Dengan membuktikan cinta orang tua pada anak-anaknya misalnya memberikan perhatian, kasih sayang dan pendidikan yang terbaik, walaupun harus mengeluarkan biaya yang mahal demi pendidikan anaknya(Ridwan, 2018; $\mathrm{Sj}$ et al., 2021). Apabila mengaku cinta pada al-Qur'an tetapi memegang dan menyentuhnya saja jarang, membacanya saja tidak, menghayati kandungannya isinya saja malas-malasan, apakah 
seperti itu dinamakan cinta kepada al-Qur'an. Dari latar belakang di atas peneliti merumuskan masalah sebagai berikut: Apakah ada pengaruh kecintaan siswa pada al-Qur'an terhadap perilaku sosial siswa di Sekolah Dasar Al Islam Plus Kabupaten Sidoarjo?. Tujuan penelitian adalah untuk membuktikan adanya pengaruh kecintaan siswa pada al-Qur'an dan dampaknya perilaku sosial siswa di Sekolah Dasar Al Islam Plus Kabupaten Sidoarjo.

\section{KAJIAN PUSTAKA}

\section{Kecintaan Siswa pada Al-Qur'an}

Banyak cara dan alternatif yang bisa dilakukan dalam menciptakan kecintaan siswa di sekolah dasar terhadap al-Qur'an, cara tersebut dapat dilakukan di dalam lingkungan sekolah yang dijadikan progam unggulan sekolah sebagai proses tumbuhnya kecintaan siswa terhadap alQur'an. Namun dalam konteks keseharian cara yang dapat digunakan yaitu dengan menumbukan rasa cinta tersebut dengan membentuk ikatan cinta dalam diri putra-putri terhadap al-Qur'an, dengan menerapkan metode motivasi dan hubungan keseharian. Sebelum memberi tugas kepada anak-anak untuk menghafal Al-Qur'an, maka terlebih dahulu harus menanamkan rasa cinta terhadap Al-Qur'an. Penanaman rasa cinta dapat dilakukan dengan menceritakan kisah-kisah dalam al-Qur'an.

\section{Perilaku Sosial}

Perilaku adalah tanggapan atau reaksi individu terhadap rangsangan atau lingkungan. Sedangkan sosial adalah berkenaan dengan orang lain atau masyarakat. Jika teori ini digabungkan maka perilaku sosial adalah tanggapan atau reaksi seseorang terhadap orang lain atau masyarakat disekitarnya (John W, 2015; Muhibbin Syah, 2013).

Perilaku sosial adalah aktifitas fisik dan psikis seseorang terhadap orang lain atau sebaliknya dalam rangka memenuhi diri atau orang lain yang sesuai dengan tuntutan sosial. Misalnya: menghormati orang lain, tolong-menolong, sopan santun, dan lain-lain (Zahro, 2018).

\section{METODE PENELITIAN}

Berdasarkan rumusan masalah yang sudah ditetapkan di atas, maka penelitian yang digunakan dalam penelitian ini adalah penelitian mix methods, antara metode penelitian kuantitatif dan kualititatif. Penelitian yang menggunakan metode campuran (mixed methods) yang dilakukan secara bersamaan dengan tujuan saling melengkapi gambaran hasil penelitian mengenai fenomena yang diteliti dan untuk memperkuat analisis penelitian (Gall et al., 2007).

Tempat dan Waktu Penelitian: Peneliti menjadikan tempat penelitiannya di Sekolah Dasar Al Islam Plus Kabupaten Sidoarjo. Waktu penelitian ini adalah bulan Januari sampai Februari 2019.

Populasi dan Sampel: Populasi adalah wilayah generalisasi yang terdiri atas objek/ subjek yang mempunyai kualitas dan karakteristik tertentu yang ditetapkan oleh peneliti untuk dipelajari kemudian diambil kesimpulannya. Sedangkan sampel adalah bagian dari populasi yang memiliki sifat sama dari objek yang merupakan sumber data. Dalam penelitian ini, peneliti menggunakan sampel kelas IV-V berjumlah 60 siswa.

Pengumpulan Data: Proses pengumpulan data dapat dilihat dari sumber data yang diperoleh. Sumber data dikelompokkan menjadi dua, yaitu sumber primer dan sumber sekunder. Sumber primer adalah sumber data yang dapat langsung memberikan data kepada peneliti. Sumber primer dalam penelitian tesis ini adalah siswa. Adapun teknik pengumpulan data yang digunakan dalam penelitian tesis ini adalah angket, observasi dan wawancara. 


\section{HASIL DAN DISKUSI}

\section{Bentuk Kecintaan Siswa pada Al-Qur'an dan Perilaku Sosialnya di SD Al Islam Plus Kabupaten Sidoarjo}

Berdasarkan hasil observasi dan wawancara yang dilakukan peneliti terhadap informan mengenai kecintaan siswa pada al-Qur'an dan perilaku sosial siswa diperoleh hasil yang hampir serupa antara jawaban yang satu dengan jawaban lainnya dari masing-masing informan. Seperti yang dikatakan oleh para informan kepada peneliti dalam wawancara bahwa anak-anak suka membaca al-Qur'an, menghafalkan al-Qur'an dan menghormati al-Qur'an. Sedangkan untuk menumbuhkan rasa cinta terhadap al-Qur'an, para informan mengungkapkan hal tersebut melalui program tahfidz al-Qur'an, melalui kisah-kisah yang disampaikan oleh guru tahfidz al-Qur'an dan perhormtan siswa terhadap al-Qur'an. Sedangkan hasil observasi yang dilakukan peneliti di SD Al Islam Plus Kabupaten Sidoarjo.

menggambarkan siswa-siswi sangat menjaga kebersihan, selain itu juga menghormati gurunya dengan berjabat tangan, membantu guru ketika sedang kesulitan, menghormati teman dan meminjamkan benda miliknya kepada temannya.

\section{Faktor yang Mempengaruhi Kecintaan Siswa pada Al-Qur'an dan Perilaku Sosialnya di SD Al Islam Plus Kabupaten Sidoarjo.}

Berdasarkan hasil observasi dan wawancara dengan para informan, peneliti telah mendapatkan data tentang faktor yang mempengaruhi kecintaan siswa pada al-Qur'an dan perilaku sosialnya di sekolah. Berdasarkan hasil wawancara kepada para infonman dapat disimpulkan bahwa pengaruh kecintaan siswa pada al-Qur'an disebabkan oleh dorongan motivasi dari orang tua, baik ayah, ibu, kakek dan nenek. Informan lainnya juga mengatakan pengaruh kecintaan siswa pada al-Qur'an ditimbulkan dari dorongan guru yang mengajarkan tahfidz alQur'an di sekolah dengan cara-cara yang inovatif seperti menceritakan kisah-kisah yang ada dalam al-Qur'an, hal demikian itu diharapkan timbul rasa kagum pada al-Qur'an sehingga anak-anak mencintai al-Qur'an. Sedangkan pengaruh perilaku siswa yang menunjukan sikap baik tersebut disebabkan dari teladan orang tua di rumah dan teladan guru di sekolah. Dorongan motivasi, perhatian dan teladan dari orang tua menyebabkan seorang anak menjadi pribadi yang kuat, berkepribadian yang baik, menghargai teman, menghormati guru, membantu sesama dan peduli terhadap lingkungan sekitarnya. Namun jika perhatian orang tua berkurang maka anak akan mencari perhatian diluar dengan menjadi pribadi yang kurang disukai oleh temannya karena perilakunya yang nakal.

\section{Al Islam Plus.}

Pengaruh Kecintaan Siswa pada Al-Qur'an terhadap Perilaku Sosial Siswa di SD

Untuk mengetahui pengaruh kecintaan siswa pada al-Qur'an dilakukan pengujian hipotesis dengan uji t. Uji t digunakan untuk mengetahui apakah variabel bebas yaitu kecintaan siswa pada al-Qur'an memiliki pengaruh yang signifikan terhadap variabel terikat yaitu perilaku sosial siswa. Hasil dari pengujian hipotesis adalah variabel kecintaan siswa pada al-Qur'an memiliki nilai thitung sebesar 6,356 dengan signifikansi sebesar 0,026. Karena thitung $>$ ttabel $(6,356>2,010)$ atau sig. $t$ $<5 \%(0,026<0,05)$, maka dapat disimpulkan bahwa variabel kecintaan siswa pada al-Qur'an berpengaruh signifikan terhadap variabel perilaku sosial siswa. Setelah ditemukan pengaruhnya, kemudian ditentukan berapa besar pengaruh kecintaan siswa pada al-Qur'an terhadap perilaku sosial siswa. Berdasarkan tabel regresi sederhana diperoleh nilai Adjusted R Square sebesar 0,546 atau $55 \%$, artinya bahwa perilaku sosial siswa dipengaruhi oleh $55 \%$ variabel bebas yaitu kecintaan siswa pada al-Qur'an. sedangkan sisanya yaitu 45\% dipengaruhi oleh variabel lain diluar variabel yang diteliti. 


\section{KESIMPULAN}

Dari hasil analisis penelitian, pembahasan serta pengujian hipotesis yang telah diuraikan pada bab-bab sebelumnya, maka kesimpulan pada penelitian ini sebagai berikut:

Bentuk kecintaan siswa pada al-Qur'an merupakan kedekatan siswa dengan al-Qur'an melalui program tahfidz seperti siswa senantiasa membaca dan menghafal al-Qur'an, meletakkan al-Qur'an di tempat yang baik dan menghormati al-Qur'annya. Sedangkan perilaku sosial siswa adalah hubungan siswa dengan siswa dan siswa dengan guru, seperti meminjamkan pensil dan penggaris, membantu temannya menyapu, berkata sopan kepada guru, berjabat tangan dengan guru, mematuhi perintah guru.

Faktor kecintaan siswa pada al-Qur'an dipengaruhi faktor pendidikan di sekolah dan keluarga di rumah. Peran sekolah dalam menumbuhkan rasa cinta diupayakan melalui program sekolah yaitu tahfidz al-Qur'an, sedangkan peran keluarga adalah memberikan keteladan kepada siswa. Sedangkan perilaku sosial dipengaruhi keteladanan guru, orang tua dan lingkungan.

Kecintaan al-Qur'an berpengaruh terhadap perilaku sosial siswa dari hasil dari uji t adalah nilai thitung sebesar 6,356 dengan signifikansi 0,026. Karena thitung $>$ ttabel $(6,356>2,010)$ atau sig. $\mathrm{t}<5 \%(0,026<0,05)$, maka disimpulkan kecintaan siswa pada al-Qur'an berpengaruh signifikan terhadap variabel perilaku sosial siswa.

\section{REFERENSI}

Damis, R. (2014). Nilai-Nilai Pendidikan Karakter pada Ajaran Cinta dalam Tasawuf. Al-Ulum, 14(1), 127-152. http://www.journal.iaingorontalo.ac.id/index.php/au/article/view/45

Gall, M. D., Gall, J. P., \& Borg, W. R. (2007). Educational research: An introduction (8th ed). Pearson/Allyn \& Bacon.

John W, S. (2015). Psikologi Pendidikan (Tri Wibowo BS, Trans.; 6th ed.). Prenada Media Grup.

Kosim, M., Kustati, M., Sabri, A., \& Mustaqim, M. (2019). Strengthening Students' Character through Tahfidz Quran in Islamic Education Curriculum. Jurnal Pendidikan Islam, 8(1), 6994. https://doi.org/10.14421/ipi.2019.81.69-94

Muhibbin Syah. (2013). Psikologi Pendidikan dengan pendekatan baru (18th ed.). Remaja Rosdakarya.

Ridwan, M. (2018). Konsep Tarbiyah, Ta'lim Dan Ta'dib Dalam Al-Qur'an. Naz̧bruna: Jurnal Pendidikan Islam, 1(1), 35-57. https://doi.org/10.31538/nzh.v1i1.41

Shihab, M. Q. (1992). Membumikan Al-Quran. Bandung: Mizan. http://saifbintoro.mywapblog.com/files/membumikan-al-quran.pdf

Sj, D. S., Maarif, M. A., \& Zamroni, A. (2021). Strategi Pengembangan Program Pembelajaran Pendidikan Agama Islam Sekolah: The Development Strategy of Islamic Religious Education Learning Programs. Tafkir: Interdisciplinary Journal of Islamic Education, 2(1), 20 40. https://doi.org/10.31538/tijie.v2i1.21

Syukriyah, N. (2019). Membumikan Al-Quran Dalam Etika Santri Kepada Kyai; Studi Tafsir Q.S Al Kahfi Ayat 66 - 70. Ną̧hruna: Jurnal Pendidikan Islam, 2(2), 209-224. https://doi.org/10.31538/nzh.v2i2.269

Zahro, I. F. (2018). Meningkatkan Perilaku Prososial Anak Dengan Teknik Islamic Storytelling Finger Doll. Nazhbruna: Jurnal Pendidikan Islam, 1(1), 80-95. https://doi.org/10.31538/nzh.v1i1.43 